Published in final edited form as:

Surg Clin North Am. 2015 October ; 95(5): 1067-1080. doi:10.1016/j.suc.2015.05.004.

\title{
Hereditary Colorectal Cancer: Genetics and Screening
}

\section{Lodewijk A.A. Brosens, MD, $\mathrm{PhD}^{1,2}$, G. Johan A. Offerhaus, MD, PhD, $\mathrm{MPH}^{3}$, and Francis M Giardiello, MD4}

Lodewijk A.A. Brosens: I.a.a.brosens@umcutrecht.nl; G. Johan A. Offerhaus: gofferha@umcutrecht.nl; Francis M Giardiello: fgiardi@jhmi.edu

${ }^{1}$ Department of Pathology, University Medical Center Utrecht (H04-312), Heidelberglaan 100, 3584 CX Utrecht, The Netherlands. Phone 31-88-7556565; Fax: 31-30-2544990 ²Department of Pathology The Johns Hopkins University School of Medicine, Baltimore, Maryland ${ }^{3}$ Department of Pathology, University Medical Center Utrecht (H04-312), Heidelberglaan 100, 3584 CX Utrecht, The Netherlands. Phone 31-88-7556565; Fax: 31-30-2544990 ${ }^{4}$ Departments of Medicine, Oncology Center, and Pathology The Johns Hopkins University School of Medicine, Baltimore, Maryland. 1830 East Monument Street, Room 431, Baltimore, MD 21205; Tel: 410-955-2635; Fax: 410- 614-8337

\section{Abstract \\ Colorectal cancer (CRC) is the third most common cancer and the third leading cause of cancer death in men and women in the United States. Each year more than 140,000 new patients are diagnosed. About $30 \%$ of patients with CRC report a family history of CRC. However, only 5\% of colorectal cancers arise in the setting of a well-established Mendelian inherited disorder such as Lynch syndrome, familial adenomatous polyposis, MUTYH-associated polyposis, juvenile polyposis, hereditary mixed polyposis, or Peutz-Jeghers. In addition, serrated polyposis is a clinically defined syndrome with multiple serrated polyps in the colorectum and an increased CRC risk for which the genetics are unknown. The majority of familial colorectal cancers arise as so called non-syndromic familial colorectal cancer and likely have a more complex multigenetic cause. This review focuses on genetic and clinical aspects of Lynch syndrome, familial adenomatous polyposis and MUTYH-associated polyposis.}

\section{Keywords}

colorectal cancer; hereditary non-polyposis colorectal cancer; Lynch syndrome; familial adenomatous polyposis; MUTYH-associated polyposis

Correspondence to: Lodewijk A.A. Brosens, 1.a.a.brosens@umcutrecht.nl; Francis M Giardiello, fgiardi@ jhmi .edu. Financial disclosures and/or conflicts of interest: The authors have nothing to disclose.

Publisher's Disclaimer: This is a PDF file of an unedited manuscript that has been accepted for publication. As a service to our customers we are providing this early version of the manuscript. The manuscript will undergo copyediting, typesetting, and review of the resulting proof before it is published in its final citable form. Please note that during the production process errors may be discovered which could affect the content, and all legal disclaimers that apply to the journal pertain. 


\section{Introduction}

With more than 140,000 newly diagnosed patients each year, colorectal cancer (CRC) is the third most common cancer and the third leading cause of cancer death in men and women in the United States.[1] In 30\% of these patients there is a family history of CRC, suggesting a heritable component, but only 5\% of CRCs arise in the setting of a well-established Mendelian inherited disorder such as Lynch syndrome, familial adenomatous polyposis (FAP), MUTYH-associated polyposis (MAP), juvenile polyposis, hereditary mixed polyposis and Peutz-Jeghers syndrome.[2-4] In addition, serrated polyposis is a clinically defined syndrome characterized by multiple serrated polyps in the colorectum and an increased CRC risk, but the genetics are not yet known.[5] (Table 1) The majority of familial CRCs (20-30\%) arise as so called nonsyndromic familial CRC and likely have a multigenetic cause.[2,5] This review discusses genetic and clinical aspects of the three main hereditary CRC syndromes: Lynch syndrome, FAP, and MAP.

\section{Lynch syndrome}

\section{Clinical features}

Lynch syndrome (LS) (also known as hereditary non-polyposis colorectal cancer; HNPCC) is an autosomal dominantly inherited syndrome caused by germline mutation in one of the mismatch repair genes ( $M L H 1, M S H 2, M S H 6, P M S 2)$ or the EpCAM gene. Due to this genetic defect LS tumors are characterized by microsatellite instability (MSI)[4]

Colorectal cancer is the major clinical consequence of LS. The lifetime risk of CRC in LS has been variably estimated and appears dependent on the mismatch repair (MMR) gene mutated. (Table 2) The average age of CRC diagnosis in LS patients is 44 to 61 years compared to 69 years in sporadic CRC. Tumors arise primarily (60-80\%) proximal to the splenic flexure.[6] A high rate of metachronous CRC (16\% at 10 years; $41 \%$ at 20 years) is noted in LS patients.[7-9] Compared with patients with attenuated FAP or MAP, LS patients develop few colorectal adenomas by age 50 (usually $<3$ adenomas).[10] The adenomacarcinoma sequence appears more rapid in LS with polyp to cancer times estimated at 35 months compared to 10-15 years in sporadic cancer.[10] The histopathology of LS colorectal cancer is often poorly differentiated, with signet cell histology, abundant extracellular mucin, tumor infiltrating lymphocytes, and a lymphoid host response to tumor. [11] LS patients have improved survival from CRC stage-for-stage compared with patients with sporadic CRC.

In addition to CRC, LS patients have increased risk for many extracolonic malignancies (Table 3). Endometrial cancer occurs in up to $54 \%$ of women with $M L H 1$ and $M S H 2$ mutations, with lower risk in those with PMS2 (15\%) mutations and much higher risk in women with MSH6 mutations (71\%). Later onset of colorectal and endometrial cancers is noted in patients with a MSH6 mutation, compared to other MMR gene defects. In addition, tumors arising in the context of MSH6 mutations can display low levels of MSI or even microsatellite stability.[6] Other neoplasms with life time risks ranging from 4 to $25 \%$ include transitional cell carcinoma of the urinary tract; adenocarcinomas of the ovary, stomach, hepatobiliary tract, and small bowel; brain cancer (glioblastoma); and cutaneous 
sebaceous neoplasms. [6, 12] An increased risk of pancreas cancer in LS has been described by some investigators.[6] The relative risk of prostate cancer may be 2-2.5 fold higher than for the general population.[6] The relationship between LS and breast cancer is unclear. Also, laryngeal and hematological malignancies have been described but a definite association to LS is not established.[6] An association between sarcoma and LS probably exists but the magnitude of risk is unclear.[6]

Phenotypic stigmata of LS are rare but can include café-au-lait spots, cutaneous sebaceous gland tumors, and keratoacanthomas.[13] Café-au-lait spots are found in a variant of LS known as constitutional mismatch repair deficiency syndrome (CMMRDS), caused by biallelic mutations of MMR genes. In addition, these patients develop CRC or other LS cancers at a very young age (childhood and teenage years), oligopolyposis in the small bowel and/or colon, brain tumors, and hematologic malignancies.[14]

Several sets of clinical criteria identify patients with LS. In 1990, the International Collaborative Group on Hereditary Nonpolyposis Colorectal Cancer (HNPCC) established criteria (Amsterdam I Criteria) for HNPCC.[15] All of the following are required to diagnose HNPCC: (1) Three or more relatives with histologically verified CRC, one of whom is a first-degree relative of the other two (FAP should be excluded); (2) CRC involving at least 2 generations; 3 ) One or more CRC cases diagnosed before the age of 50. More sensitive criteria called Amsterdam II criteria were established in 1999.[16] Amsterdam II criteria include some extracolonic tumors commonly seen in LS as qualifying cancers, in particular cancer of the endometrium, small bowel, or urothelium. Today other LS-related tumors would also be included such as cancer of the ovary, stomach, hepatobiliary tract, and brain. The Revised Bethesda Guidelines are a third set of clinicopathologic criteria developed to identify individuals who deserve investigation for LS by evaluation of MSI and/or immunohistochemistry testing of their tumors.[17]

\section{Genetic defect}

Germline mutations in one of several DNA mismatch repair genes, specifically, $M L H 1$, MSH2, MSH6 and PMS2 cause Lynch syndrome. These genes maintain fidelity of the DNA during replication by correction of nucleotide base mis-pairs and small insertions or deletions generated by mis-incorporations or slippage of DNA-polymerase during DNA replication. [2, 4] Mutations of the EPCAM gene, located just upstream from the $M S H 2$ gene, results in silencing of the $M S H 2$ gene in tissues that express EPCAM and produces a phenotype very similar to LS.[18] Mutations in $M L H 1$ and $M S H 2$ account for up to $90 \%$ and MSH6 about $10 \%$ and PMS2 mutations in up to 6\% of families with LS.[4] Rare patients with a germline epimutation causing $M L H 1$ hypermethylation have been described.[19]

LS tumors are characterized by MSI which is ubiquitous mutations at simple repetitive sequences (microsatellites) found in the tumor DNA (but not in DNA of adjacent normal colorectal mucosa) of individuals with MMR gene defects. MSI in a CRC indicates a defect in one of the MMR genes caused by either somatic inactivation (hypermethylation of the MLHI promoter in sporadic CRC) or a germline MMR gene defect (Lynch syndrome). MSI is found in most (>90\%) colon malignancies in patients with LS and in $12 \%$ of patients with sporadic CRC. MSI is graded as MSI-High (MSI-H) (>30\% of markers are unstable); MSI- 
Low (MSI-L) (<30\% of markers are unstable); MS-Stable (MSS) (no markers are unstable). [4]

Immunohistochemistry testing of CRC utilizing antibodies to the MMR gene proteins MLH1, MSH2, MSH6, PMS2 evaluates for the loss of MMR protein expression and assists in the identification of patients with LS. Deleterious alterations (either germline or somatic) in specific DNA MMR genes are indicated by loss or partial production of the MMR protein produced by that gene.[4]

Somatic mutations in the $B R A F$ gene, largely at codon 600 , are noted in $15 \%$ of sporadic CRCs but not in LS tumors.[20] Consequently, the presence of a BRAF mutation in an MSI$\mathrm{H}$ colorectal cancer is evidence against presence of LS.[4]

\section{Genetic testing}

Identification of patients with LS can be done by application of the Amsterdam or Revised Bethesda Criteria, use of computer models of risk, tumor testing, or germline testing. Because, utilization of clinical criteria and modeling to identify patients with LS has less than optimal sensitivity and efficiency, universal screening for LS has also been endorsed by EGAPP (Evaluation of Genomic Application in Practice and Prevention) and by Healthy People 2020, the National Comprehensive Cancer Network (NCCN), and the Multi-Society Task Force on Colorectal Cancer (MSTF).[6, 21] The MSTF recommends that this is done for all CRCs, or CRC diagnosed at age 70 or less, and in individuals older than 70 with a family history concerning for LS. Analysis may be done by immunohistochemical testing for the MLH1/MSH2/MSH6/PMS2 proteins and/or MSI testing. Tumors with loss of MLH1 should undergo analysis for $B R A F$ mutation or $M L H I$ promoter hypermethylation. If universal screening reveals evidence of LS, patients should be referred for genetic evaluation which can involve germline testing for a MMR gene mutation $(M L H 1, M S H 2$, MSH6, PMS2) or the EPCAM gene. Also, patients with endometrial cancer before age 50, a known familial MMR gene mutation, fulfilling Amsterdam criteria or revised Bethesda guidelines or a personal risk of $>5 \%$ of LS based on prediction models should undergo genetic evaluation for LS.

\section{Management}

Patients with LS are at increased risk of colorectal and extracolonic cancers at early ages. Although there is insufficient evidence to assess the benefit of annual history, physical examination, and patient and family education, expert opinion would recommend this practice starting at age 20-25.

A variety of screening recommendations exists for patients at risk (first-degree relatives of those affected) or affected with LS.[6] Screening for CRC by colonoscopy is recommended every one to two years beginning between ages 20-25 or 2-5 years before the youngest age of CRC diagnosis in the family if diagnosed before age 25. Screening for endometrial cancer should be offered to women by pelvic examination and endometrial sampling annually starting at age 30-35 years. Screening for ovarian cancer should be offered to women with LS by transvaginal ultrasound annually starting at age 30-35 years. Hysterectomy and 
bilateral salpingo-oophorectomy should be recommended to women with LS who have finished childbearing or at age 40. Screening for gastric cancer should be considered in persons with LS by esophagogastroduodenoscopy with gastric biopsy of the antrum at age 30-35 with Helicobacter pylori eradication when found. Subsequent, surveillance every 2-3 years can be considered based on individual patient risk factors. Screening for cancer of the urinary tract should be considered with urinalysis annually starting at age 30-35.

Colectomy with ileorectal anastomosis is the primary treatment of patients affected with LS with CRC or colon neoplasia not removable by endoscopy. With partial colectomy a high 10 -year cumulative risk of metachronous colorectal cancer (16-19\%) is reported, even in patients undergoing vigilant colonoscopic surveillance and increases with longer observation.[7-9] This risk is substantially reduced if a subtotal or total colectomy is performed (0-3.4\%).[7-9] No difference in global quality of life was noted between LS patients with partial or subtotal colectomy, though functional outcome (stool frequency, stool related aspects, social impact) was worse after subtotal colectomy.[22] Comparison of life expectancy gained performing total colectomy versus hemicolectomy in LS patients at ages 27, 47, and 67 by Markov modeling was 2.3, 1, 0.3 years, respectively.[23] These investigators concluded that total colectomy is the preferred treatment in LS but hemicolectomy may be an option in older patients. Although most LS colorectal cancers are right-sided, up to $20 \%$ occur in the rectum. When this happens, clinical decision making should include use of neo-adjuvant chemoradiation and consideration of total protocolectomy and ileal pouch-anal anastomosis (IPAA). Kalady et al. found a risk of metachronous advanced neoplasia (cancer and severe dysplasia) of 51\% in HNPCC patients who had an low anterior resection for rectal cancer.[24] Win et al. found the overall risk of cancer to be $24.5 \%$ and a cumulative risk to 30 years of $69 \%$.[9] Total proctocolectomy and IPAA is thus an important option to discuss with LS patients with rectal cancer.

Growing but not conclusive evidence exists that use of aspirin is beneficial in preventing cancer in LS. Treatment of an individual patient with aspirin is a consideration after discussion of patient-specific risks, benefits, and uncertainties of treatment is conducted.[25]

\section{Familial adenomatous polyposis}

\section{Clinical features}

Familial adenomatous polyposis is an autosomal dominant inherited syndrome caused by germline mutation in the APC (Adenomatous Polyposis Coli) gene.[26] Depending on the location of the mutation in the $A P C$ gene, FAP can manifest either in a classic form (classic FAP) or in a less severe, attenuated form (attenuated FAP; AFAP).[3, 27] The prevalence of FAP is about 1:13,000.

Classic FAP is characterized by development in teenage years of hundreds to thousands adenomatous polyps (a minimum of 100) throughout the colorectum. About $50 \%$ of patients developed adenomas by age 15 and $95 \%$ by age 35 . If left untreated, FAP patients will develop CRC at an average age of 39 (range 35-43 year).[28] 
Attenuated FAP is defined by the presence of an average of 30 polyps (oligopolyposis).[2] The diagnosis should be considered in patients 40-50 year old with 10-100 adenomas cumulatively. Patients with AFAP have a 70\% lifetime risk of CRC, about 12 years later than in classic FAP.[2, 28] Of note, oligopolyposis can be an expression of a germline APC mutation or a biallelic MUTYH mutation (MUTYH-polyposis, see next section).[29]

A variety of benign and malignant extracolonic manifestations have been described in FAP. Of concern are duodenal adenomas and duodenal cancer.[30] Duodenal adenomas are present in $30-70 \%$ of FAP patients with a lifetime risk of almost $100 \%$. The lifetime risk of duodenal adenocarcinoma is $4-10 \%$. The Spigelman classification system is used to grade severity and guide clinical management of duodenal polyposis. (Table 4 and 5) [2, 30, 31] Adenomas in the jejunum and ileum occur sporadically. Most gastric polyps are benign fundic gland polyps, present in 50\% of patients. Gastric adenomas occur in about $10 \%$ of FAP patients, usually in the antrum. The lifetime risk of gastric cancer is low $(0.6-1 \%)$.[2, 31]

Less frequent extraintestinal malignancies in FAP are hepatoblastoma and cancers of the thyroid, biliary tree, pancreas and central nervous system.[3, 28, 32] The combination of colorectal polyposis and a primary central nervous system malignancy (medulloblastoma) is called Crails syndrome.

Desmoid tumors occur in about 10\% of FAP patients and are usually located in the small intestinal mesentery, abdominal wall or extremities.[33] Intra-abdominal desmoid tumors have a poor prognosis. Although desmoid tumors have no metastatic potential, local expansion and invasive growth with damage to intra-abdominal structures and peri-operative complications are the cause of death in a significant proportion of FAP patients.[3]

Benign extraintestinal manifestations can be used as diagnostic tools in the examination of first degree relatives of patients with FAP. [3, 34] Congenital hypertrophy of the retinal pigment epithelium (CHRPE) are discrete round-oval darkly pigmented areas in the ocular fundus ranging in size from $0.1-1$ optic-disc diameter found in $>90 \%$ of FAP patients. CHRPE is asymptomatic but bilateral and/or multiple (>4) CHRPE is a clinical marker for asymptomatic carriers in families with FAP.[34, 35]

Several oral and maxillofacial lesions can be found in FAP patients. Occult radio-opaque jaw lesions are osteosclerotic bone lesions found on panoramic jaw radiographs and used as predictors for polyp development in FAP families with jaw lesions.[36] Oral mucosal vascular density may be a clinical marker of FAP and others at high risk for CRC.[37] In addition, FAP patients have an increased risk of jaw osteomas (in 46-93\% of FAP patients), odontomas (in $9-83 \%$ of FAP patients), supernumerary (in 11-27\% of FAP patients) or unerupted (in 4-38\% of FAP patients) teeth.[38] Lastly, nasopharyngeal angiofibroma is 25 times more common in FAP patients than in the general population.[39] Cutaneous lesions found in FAP patients are lipomas, fibromas, sebaceous and epidermoid cysts. In older literature, the combination of colorectal adenomatous polyposis and extraintestinal manifestations was designated as Gardner syndrome but it is now recognized that that most FAP patients have one or more extracolonic manifestation.[28] 


\section{Genetic defect}

The $A P C$ gene, a tumor suppressor gene on chromosome 5q21, was identified as the cause of FAP in 1991.[26] The $A P C$ gene has 15 exons and encodes a 2843 amino acid protein with a key function in the Wnt-signaling pathway. Germline mutations in the APC gene are found in $80-90 \%$ of patients with classic FAP and in $10-30 \%$ of patients with AFAP.[3] More than 300 different $A P C$ gene mutations have been reported. Most are frameshifts due to insertions or deletions, or nonsense mutations, leading to truncated APC proteins. A high frequency of somatic $A P C$ mutations is found in the mutation cluster region in the $5^{\prime}$ part of exon 15 , between codons 1286 and 1513 and in codon 1309.[28, 40]

Genotype-phenotype studies showed that $A P C$ mutations in the central part of the gene (between codons 160 and 1393) result in classic FAP. Mutations between codon 1250 and codon 1464 cause profuse polyposis (>1000 colorectal polyps). In contrast, mutations in the $3^{\prime}$ and $5^{\prime}$ ends of the gene predispose to AFAP.[27, 40] Genotype-phenotype correlations for duodenal polyposis in FAP are less clear, but may correlate with mutations distal to codon 1400 in exon 15.[30]

Several genotype-phenotype correlations have been reported. These include multiplicity of extraintestinal lesions with mutations in codons 1465, 1546 and 2621 of the APC gene; ocular fundus lesions (CHRPE) with mutations between codons 463 and 1444; thyroid cancer with mutations in the $5^{\prime}$ part of exon 15 (outside codons 1286-1513) at codon 1061; and desmoid tumors with mutations $3^{\prime}$ of codon 1444. APC mutation between codons 697-1224 has been linked with a 3-fold increased risk of brain tumors in general, and a 13fold increased risk of medulloblastoma specifically.[32] However, caution should be taken in genetic counseling of FAP patients since considerable intra- and interfamilial phenotypic variability exists.

Of note, the APC $11307 \mathrm{~K}$ gene mutation is found in $6 \%$ of Ashkenazi Jews. This T to A mutation at nucleotide 3920 leads to an extended mononucleotide tract of eight consecutive adenine base pairs in one of the APC alleles. Although the predicted missense mutation itself does not lead to a dysfunctional APC protein, it leads to susceptibility to additional somatic mutations in this $A P C$ allele due to polymerase slipping during DNA replication. The $11307 \mathrm{~K}$ mutation confers a two-fold increased risk of CRC and is associated with an increased number of adenomas (sometimes oligopolyposis as in AFAP) and CRCs per patient. [41]

\section{Management}

Colorectum - patients at risk of FAP (first degree relatives of FAP patients) should be screened between age 10-12. APC gene testing is the test of choice (Table 6). If no informative genetic test can be obtained, patients should have endoscopic screening with a yearly sigmoidoscopy or colonoscopy starting between age 10 to 15 . Each subsequent decade screening frequency can be reduced by a year up to age 50 when patients should be screened every 3 years.[28]

For individuals suspected of AFAP, gene testing is recommended if 20 or more cumulative colorectal adenomas are found. Patients at risk for AFAP should receive endoscopic 
screening with colonoscopy at age 12,15, 18 and 21, and then every 2 years.[28] About $33 \%$ of AFAP patients can be managed long-term endoscopically by polypectomy.[2]

Prophylactic colectomy should be performed shortly after diagnosis of FAP to prevent CRC development. Surgical options include subtotal colectomy with ileorectal anastomosis, total proctocolectomy with Brooke ileostomy (or with continent ileostomy) and total proctocolectomy with mucosal proctectomy and ileo-anal pull-trough (with pouch formation). Life-long endoscopic surveillance of any remaining rectal segment every six months is required since approximately $25 \%$ of these patients develop rectal cancer. Eventually $16-33 \%$ of these patients need proctocolectomy. Proctocolectomy with either ileostomy or restorative proctocolectomy is indicated for patients with dense polyposis and carcinoma at the time of subtotal colectomy in view of a very high risk of rectal cancer.[2, 3]

Chemopreventive strategies, particularly with non-steroidal anti-inflammatory drugs (NSAIDs), have been studied in FAP patients to delay adenoma development in the upper and lower gastrointestinal tract and to prevent adenomas recurrence in the retained rectum after rectal sparing surgery. The NSAID sulindac and selective cyclooxygenase-2 inhibitor celecoxib reduced the number and size of colorectal polyps in the short-term. Long-term use of sulindac reduced polyp number and prevented recurrence of high-grade adenomas in the retained rectal segment although effects are variable and stringent endoscopic surveillance remains essential. The main benefit of NSAIDs may be more straightforward endoscopic surveillance due to decreased numbers and smaller polyps. Primary chemoprevention of adenomas in phenotypically unaffected $A P C$ gene mutation positive patients did not prevent development of polyposis. Curcumin and eicosapentaenoic acid have shown efficacy in small chemoprevention trials and are being further studied.[42]

Upper gastrointestinal tract-Upper gastrointestinal endoscopy is indicated for FAP patients between age 25 and 30. Endoscopic surveillance regiments best dictated by the Spigelman-stage of duodenal polyposis.[30, 31] (Table 4 and 5) Endoscopic treatment of duodenal polyposis is troubled by high recurrence rates, varying from 50 to $100 \%$. The benefit of endoscopic therapy is thus controversial, but may be useful in individual cases and to postpone surgery.[30] Surgery for duodenal polyposis is indicated in patients with Spigelman stage IV duodenal polyposis. Surgical options are local surgery (duodenotomy with polypectomy and/or ampullectomy), pancreas and pylorus preserving duodenectomy or classical pancreaticoduodenectomy. Morbidity and mortality of the type of surgery should be weighed against the risk duodenal malignancy.[30]

Chemoprevention with NSAIDs of duodenal polyps seems less effective than in the colorectum. Although some groups find modest regression of small duodenal adenomas in patients treated with $400 \mathrm{mg}$ sulindac or $800 \mathrm{mg}$ celecoxib, most reports find no significant effect on duodenal polyposis.[30]

Desmoid tumors-Desmoid tumors are an important cause of morbidity and mortality in FAP. Surgery seems to be the treatment of choice for extra-abdominal and abdominal wall desmoids. The optimal treatment for intra-abdominal desmoids is less clear. Comparable outcomes have been reported for a conservative approach and surgery. Pharmacological 
therapies with NSAIDs and anti-estrogens showed comparable outcomes. Combination chemotherapy including doxorubicin seems to be the best option for progressively growing intra-abdominal desmoids.[3, 43]

\section{MUTYH-associated polyposis}

\section{Clinical features}

MUTYH-associated polyposis is an autosomal recessively inherited syndrome caused by germline mutation of both alleles of the MUTYH gene (also known as MYH gene).[44] The colonic phenotype mimics that of AFAP. Most patients have between 10 to a few hundred adenomas. Alternatively, biallelic germline $M U T Y H$ mutations have been found in some patients with early onset CRC and few to zero polyps.[44] Although most polyps in MAP are adenomas, patients can present with serrated polyps or a mixture of adenomas and serrated polyps.[45] Colorectal polyps usually develop around age 40. The risk of CRC in MAP is $19 \%$ by age 50 and $43 \%$ by age 60 . The average age of CRC onset is 48 years. Relatives of MAP patients with a heterozygous $M U T Y H$ mutation have a risk of CRC comparable to that of first-degree relatives of patients with sporadic CRC.[46]

Gastric and duodenal polyps occur in 11-17\% of MAP patients. The lifetime risk of duodenal cancer is about 4\%.[47] A statistically non-significant trend towards an increased risk of gastric cancer is reported.[44, 47]

Compared to the general population, MAP patients have an almost doubled risk of extraintestinal malignancies, including ovarian, bladder, skin and possibly breast cancer. However, based on the spectrum of cancers and the relatively late age of onset, intensive surveillance measures for extraintestinal malignancies are not recommended.[47]

\section{Genetic defect}

MUTYH gene consists of 16 exons and is located on chromosome 1p34.3-p32.1. MUTYH encodes a DNA glycosylase involved in base excision repair (BER) of 8-oxoG:A mismatches caused by oxidative DNA damage.

Biallelic MUTYH mutations are found in about $30 \%$ of patients with $10-100$ polyps and in $15 \%$ of patients with $100-1000$ polyps. Especially in patients with $>15$ synchronous adenomas and $\mathrm{CRC}$ before age 50 there is a very high chance of finding biallelic $M U T Y H$ mutations.[44] Table 7 summarizes indications for MUTYH germline testing.

More than 100 unique MUTYH gene mutations have been reported. Most of these are missense mutations although small deletions, duplications and insertions also occur. Y179C and G396D are hotspot mutations in Caucasian populations. At least one Y179C or G396D mutation is present in $90 \%$ of Caucasians MAP patients and biallelic mutation of Y179C and/or G396D is present in 70\%. However, there seems to be ethnic and regional differentiation in the MUTYH mutation spectrum.[44] Despite these population specific mutations the entire MUTYH gene should be screened for mutations. 
Genotype-phenotype studies have shown that patients with homozygous G396D mutations or compound heterozygous G396D/Y179C mutations have a less severe phenotype than patients with biallelic Y179C mutation. This is consistent with the greater reduction in glycolylase activity of Y179C mutations than G396D mutations. Patients with at least one G396D allele present later with MAP and have a significantly lower risk and later age of CRC diagnosis than patients with biallelic Y179C mutation. The mean ages of CRC diagnosis were 58 years (homozygous G396D), 52 years (compound heterozygous G396D/ Y179C) and 46 years (homozygous Y179C) respectively.[48] Interestingly, patients with a compound mutation of G396D and another mutation that Y179C did not show a milder phenotype.

\section{Management}

Patients with MAP should undergo colonoscopy every 1 to 2 year. Subtotal colectomy is recommended if endoscopic management fails or if CRC develops. Currently it is unclear if patients with monoallelic MUTYH mutation should receive more intensive CRC screening than average risk individuals.

Recommendations for screening and management of the upper gastrointestinal tract of MAP patients are comparable to those for FAP patients. Upper gastrointestinal tract screening should start around age 30 and, depending on the findings, be repeated at intervals similar to FAP (Table 5).

\section{Conclusion}

Colorectal cancer is the third most common cancer. Although most CRCs arise in a sporadic setting, without a clear familial or hereditary component, recognition of patients with a hereditary form of CRC is vital in view of the consequences for the patients and their families. Also, hereditary CRC syndromes are paradigms for gastrointestinal carcinogenesis in general. FAP was the first polyposis syndrome molecularly characterized by the discovery of the $A P C$ gene. Tumorigenesis in FAP is considered the prototype of the adenomacarcinoma sequence in the large bowel due to disrupted 'gatekeeper' function of APC and subsequent Wnt activation accompanied by an accumulation of genetic changes and resultant clonal expansion.[26] The majority (60\%) of all CRCs follow this classic adenomacarcinoma pathway characterized by Wnt activation and chromosomal instability.[49]

Lynch syndrome is the prototype of CRC caused by a "caretaker" defect, i.e. deficiency of one of the MMR genes leading to cancers with microsatellite instability. About $15 \%$ of all CRCs are characterized by MMR deficiency and MSI. Most of these MSI colorectal cancers are caused by somatic hypermethylation of the MMR gene $M L H 1$, whereas a minority are caused by an inherited MMR gene defect as in Lynch syndrome.[49]

For decades CRC was classified as either chromosomal instable or chromosomal stable/ microsatellite unstable and all colorectal carcinomas were believed to arise from conventional adenomas via the suppressor pathway initiated with $A P C$ gene mutation (the classic Fearon-Vogelstein model). Elucidation of the serrated pathway to colorectal cancer in the past decade revealed that molecular classification of CRC is more complex and 
heterogeneous and that up to $25 \%$ of CRCs develop trough the serrated pathway. The recognition of the serrated pathway to CRC has shifted understanding of the molecular basis of CRC and changed clinical practice. Whereas polyps with a serrated architecture were previously considered harmless lesions, now larger and right sided serrated polyps are recognized as bona fide CRC precursor lesions that should be removed like conventional adenomas. Although the genetics of serrated polyposis syndrome are not yet understood, studying this intriguing syndrome will undoubtedly further increase our understanding of colorectal carcinogenesis in a similar way as studies on other inherited colorectal cancer syndromes.[26, 49]

\section{Acknowledgments}

We are indebted to Ms. Linda Welch for technical support.

Funding support: The John G Rangos Sr. Charitable Foundation; The Clayton Fund; NIH grant P50 CA62924; the Union for International Cancer Control (UICC) Yamagiwa-Yoshida Memorial International Cancer Study Grants; and the Nijbakker-Morra Stichting

\section{References}

1. Siegel R, Desantis C, Jemal A. Colorectal cancer statistics, 2014. CA Cancer J Clin. 2014; 64:10417. [PubMed: 24639052]

2. Jasperson KW, Tuohy TM, Neklason DW, et al. Hereditary and familial colon cancer. Gastroenterology. 2010; 138:2044-58. [PubMed: 20420945]

3. Brosens LA, van Hattem WA, Jansen M, et al. Gastrointestinal polyposis syndromes. Curr Mol Med. 2007; 7:29-46. [PubMed: 17311531]

4. Jansen M, Menko FH, Brosens LA, et al. Establishing a clinical and molecular diagnosis for hereditary colorectal cancer syndromes: Present tense, future perfect? Gastrointest Endosc. 2014; 80:1145-55. [PubMed: 25434663]

5. Jass JR. Gastrointestinal polyposes: clinical, pathological and molecular features. Gastroenterol Clin North Am. 2007; 36:927-46. viii. [PubMed: 17996798]

6. Giardiello FM, Allen JI, Axilbund JE, et al. Guidelines on genetic evaluation and management of Lynch syndrome: a consensus statement by the US Multi-Society Task Force on colorectal cancer. Gastroenterology. 2014; 147:502-26. [PubMed: 25043945]

7. de Vos tot Nederveen Cappel WH, Nagengast FM, Griffioen G, et al. Surveillance for hereditary nonpolyposis colorectal cancer: a long-term study on 114 families. Dis Colon Rectum. 2002; 45:1588-94. [PubMed: 12473880]

8. Parry S, Win AK, Parry B, et al. Metachronous colorectal cancer risk for mismatch repair gene mutation carriers: the advantage of more extensive colon surgery. Gut. 2011; 60:950-7. [PubMed: 21193451]

9. Win AK, Parry S, Parry B, et al. Risk of metachronous colon cancer following surgery for rectal cancer in mismatch repair gene mutation carriers. Ann Surg Oncol. 2013; 20:1829-36. [PubMed: 23358792]

10. Edelstein DL, Axilbund J, Baxter M, et al. Rapid development of colorectal neoplasia in patients with Lynch syndrome. Clin Gastroenterol Hepatol. 2011; 9:340-3. [PubMed: 21070872]

11. Peltomäki, PT.; Offerhaus, GJ.; Vasen, HFA. Lynch syndrome. In: Bosman, FT.; Carneiro, F.; Hruban, RH.; Theise, ND., editors. WHO Classification of Tumours of the Digestive System. Lyon: IARC Press; 2010.

12. Bonadona V, Bonaiti B, Olschwang S, et al. Cancer risks associated with germline mutations in MLH1, MSH2, and MSH6 genes in Lynch syndrome. JAMA. 2011; 305:2304-10. [PubMed: 21642682]

13. Trimbath JD, Petersen GM, Erdman SH, et al. Cafe-au-lait spots and early onset colorectal neoplasia: a variant of HNPCC? Fam Cancer. 2001; 1:101-5. [PubMed: 14574005] 
14. Wimmer K, Kratz CP, Vasen HF, et al. Diagnostic criteria for constitutional mismatch repair deficiency syndrome: suggestions of the European consortium 'care for CMMRD' (C4CMMRD). J Med Genet. 2014; 51:355-65. [PubMed: 24737826]

15. Vasen HF, Mecklin JP, Khan PM, et al. The International Collaborative Group on Hereditary NonPolyposis Colorectal Cancer (ICG-HNPCC). Dis Colon Rectum. 1991; 34:424-5. [PubMed: 2022152]

16. Vasen HF, Watson P, Mecklin JP, et al. New clinical criteria for hereditary nonpolyposis colorectal cancer (HNPCC, Lynch syndrome) proposed by the International Collaborative group on HNPCC. Gastroenterology. 1999; 116:1453-6. [PubMed: 10348829]

17. Umar A, Boland CR, Terdiman JP, et al. Revised Bethesda Guidelines for hereditary nonpolyposis colorectal cancer (Lynch syndrome) and microsatellite instability. J Natl Cancer Inst. 2004; 96:261-8. [PubMed: 14970275]

18. Ligtenberg MJ, Kuiper RP, Chan TL, et al. Heritable somatic methylation and inactivation of MSH2 in families with Lynch syndrome due to deletion of the $3^{\prime}$ exons of TACSTD1. Nat Genet. 2009; 41:112-7. [PubMed: 19098912]

19. Hitchins MP, Ward RL. Constitutional (germline) MLH1 epimutation as an aetiological mechanism for hereditary non-polyposis colorectal cancer. J Med Genet. 2009; 46:793-802. [PubMed: 19564652]

20. Domingo E, Niessen RC, Oliveira C, et al. BRAF-V600E is not involved in the colorectal tumorigenesis of HNPCC in patients with functional MLH1 and MSH2 genes. Oncogene. 2005; 24:3995-8. [PubMed: 15782118]

21. Evaluation of Genomic Applications in P, Prevention Working G. Recommendations from the EGAPP Working Group: genetic testing strategies in newly diagnosed individuals with colorectal cancer aimed at reducing morbidity and mortality from Lynch syndrome in relatives. Genet Med. 2009; 11:35-41. [PubMed: 19125126]

22. Haanstra JF, de Vos Tot Nederveen Cappel WH, Gopie JP, et al. Quality of life after surgery for colon cancer in patients with Lynch syndrome: partial versus subtotal colectomy. Dis Colon Rectum. 2012; 55:653-9. [PubMed: 22595844]

23. de Vos tot Nederveen Cappel WH, Buskens E, van Duijvendijk P, et al. Decision analysis in the surgical treatment of colorectal cancer due to a mismatch repair gene defect. Gut. 2003; 52:17525. [PubMed: 14633956]

24. Kalady MF, Lipman J, McGannon E, et al. Risk of colonic neoplasia after proctectomy for rectal cancer in hereditary nonpolyposis colorectal cancer. Ann Surg. 2012; 255:1121-5. [PubMed: 22549751]

25. Burn J, Bishop DT, Mecklin JP, et al. Effect of aspirin or resistant starch on colorectal neoplasia in the Lynch syndrome. N Engl J Med. 2008; 359:2567-78. [PubMed: 19073976]

26. Kinzler KW, Vogelstein B. Lessons from hereditary colorectal cancer. Cell. 1996; 87:159-70. [PubMed: 8861899]

27. Spirio L, Olschwang S, Groden J, et al. Alleles of the APC gene: an attenuated form of familial polyposis. Cell. 1993; 75:951-7. [PubMed: 8252630]

28. Trimbath JD, Giardiello FM. Review article: genetic testing and counselling for hereditary colorectal cancer. Aliment Pharmacol Ther. 2002; 16:1843-57. [PubMed: 12390093]

29. Nielsen M, Hes FJ, Nagengast FM, et al. Germline mutations in APC and MUTYH are responsible for the majority of families with attenuated familial adenomatous polyposis. Clin Genet. 2007; 71:427-33. [PubMed: 17489848]

30. Brosens LA, Keller JJ, Offerhaus GJ, et al. Prevention and management of duodenal polyps in familial adenomatous polyposis. Gut. 2005; 54:1034-43. [PubMed: 15951555]

31. Spigelman AD, Williams CB, Talbot IC, et al. Upper gastrointestinal cancer in patients with familial adenomatous polyposis. Lancet. 1989; 2:783-5. [PubMed: 2571019]

32. Attard TM, Giglio P, Koppula S, et al. Brain tumors in individuals with familial adenomatous polyposis: a cancer registry experience and pooled case report analysis. Cancer. 2007; 109:761-6. [PubMed: 17238184] 
33. Nieuwenhuis MH, De Vos Tot Nederveen Cappel W, Botma A, et al. Desmoid tumors in a dutch cohort of patients with familial adenomatous polyposis. Clin Gastroenterol Hepatol. 2008; 6:2159. [PubMed: 18237870]

34. Giardiello FM, Offerhaus GJ, Traboulsi EI, et al. Value of combined phenotypic markers in identifying inheritance of familial adenomatous polyposis. Gut. 1991; 32:1170-4. [PubMed: 1659551]

35. Traboulsi EI, Krush AJ, Gardner EJ, et al. Prevalence and importance of pigmented ocular fundus lesions in Gardner's syndrome. N Engl J Med. 1987; 316:661-7. [PubMed: 3821797]

36. Offerhaus GJ, Levin LS, Giardiello FM, et al. Occult radiopaque jaw lesions in familial adenomatous polyposis coli and hereditary nonpolyposis colorectal cancer. Gastroenterology. 1987; 93:490-7. [PubMed: 3038660]

37. Edelstein DL, Giardiello FM, Basiri A, et al. A new phenotypic manifestation of familial adenomatous polyposis. Fam Cancer. 2011; 10:309-13. [PubMed: 21547505]

38. Wijn MA, Keller JJ, Giardiello FM, et al. Oral and maxillofacial manifestations of familial adenomatous polyposis. Oral Dis. 2007; 13:360-5. [PubMed: 17577321]

39. Giardiello FM, Hamilton SR, Krush AJ, et al. Nasopharyngeal angiofibroma in patients with familial adenomatous polyposis. Gastroenterology. 1993; 105:1550-2. [PubMed: 8224661]

40. Friedl W, Caspari R, Sengteller M, et al. Can APC mutation analysis contribute to therapeutic decisions in familial adenomatous polyposis? Experience from 680 FAP families. Gut. 2001; 48:515-21. [PubMed: 11247896]

41. Laken SJ, Petersen GM, Gruber SB, et al. Familial colorectal cancer in Ashkenazim due to a hypermutable tract in APC. Nat Genet. 1997; 17:79-83. [PubMed: 9288102]

42. Kim B, Giardiello FM. Chemoprevention in familial adenomatous polyposis. Best Pract Res Clin Gastroenterol. 2011; 25:607-22. [PubMed: 22122775]

43. Nieuwenhuis MH, Mathus-Vliegen EM, Baeten CG, et al. Evaluation of management of desmoid tumours associated with familial adenomatous polyposis in Dutch patients. Br J Cancer. 2011; 104:37-42. [PubMed: 21063417]

44. Nielsen M, Morreau H, Vasen HF, et al. MUTYH-associated polyposis (MAP). Crit Rev Oncol Hematol. 2011; 79:1-16. [PubMed: 20663686]

45. Boparai KS, Dekker E, Van Eeden S, et al. Hyperplastic polyps and sessile serrated adenomas as a phenotypic expression of MYH-associated polyposis. Gastroenterology. 2008; 135:2014-8. [PubMed: 19013464]

46. Jones N, Vogt S, Nielsen M, et al. Increased colorectal cancer incidence in obligate carriers of heterozygous mutations in MUTYH. Gastroenterology. 2009; 137:489-94. 494 e1. quiz 725-6.

47. Vogt S, Jones N, Christian D, et al. Expanded extracolonic tumor spectrum in MUTYH-associated polyposis. Gastroenterology. 2009; 137:1976-85. 1-10. [PubMed: 19732775]

48. Nielsen M, Joerink-van de Beld MC, Jones N, et al. Analysis of MUTYH genotypes and colorectal phenotypes in patients With MUTYH-associated polyposis. Gastroenterology. 2009; 136:471-6. [PubMed: 19032956]

49. Jass JR. Classification of colorectal cancer based on correlation of clinical, morphological and molecular features. Histopathology. 2007; 50:113-30. [PubMed: 17204026] 


\section{Key points}

- Thirty percent of patients with colorectal cancer have a family history of colorectal cancer

- Only 5\% of colorectal cancers arise in the setting of a Mendelian inherited syndrome

- Lynch syndrome is an autosomal dominant inherited disorder caused by germline mutation in one of the mismatch repair genes (MLH1, MSH2, MSH6, PMS2) or EpCAM gene and characterized by microsatellite unstable cancers

- Patients with Lynch syndrome have a high risk of colorectal cancer (50-80\% lifetime risk) and extracolonic malignancies

- Familial adenomatous polyposis is an autosomal dominant inherited disorder caused by germline mutation of the APC gene and characterized by hundreds to thousands adenomatous polyps in the colorectum

- If untreated, the lifetime risk of colorectal cancer in familial adenomatous polyposis is nearly $100 \%$, and the average age of CRC diagnosis is 39 years

- Attenuated FAP is characterized by fewer colorectal adenomatous polyps and a $70 \%$ lifetime risk of CRC.

- MUTYH-associated polyposis in an autosomal recessive inherited disorder caused by germline mutation in the $M U T Y H$ gene characterized by a polyposis phenotype similar to AFAP and associated with an $80 \%$ lifetime risk of colorectal cancer 
Table 1

\section{Colorectal cancer syndromes}

\begin{tabular}{|l|l|l|}
\hline Syndrome & Genes & Mode of inheritance \\
\hline Lynch syndrome & $M L H 1, M S H 2$, MSH6, PMS2, or EpCAM & Autosomal dominant \\
\hline (Attenuated) Familial adenomatous polyposis & APC & Autosomal dominant \\
\hline MUTYH-associated polyposis & MUTYH $(M Y H)$ & Autosomal recessive \\
\hline Peutz-Jeghers syndrome & LKB1 $($ STK11) & Autosomal dominant \\
\hline Juvenile polyposis syndrome & SMAD4 $(\sim 30 \%)$ BMPR1A $(\sim 20 \%)$ & Autosomal dominant \\
\hline Hereditary mixed polyposis syndrome & GREM1 & Autosomal dominant \\
\hline Serrated polyposis syndrome & unknown & unknown \\
\hline
\end{tabular}


Table 2

Risk of colorectal cancer by age 70 in Lynch Syndrome

\begin{tabular}{|l|l|l|}
\hline Gene mutation carriers & Risk & Average age of diagnosis (years) \\
\hline Sporadic colorectal cancer & $5.5 \%$ & 69 \\
\hline MLH1 and $M S H 2$ & $22-74 \%$ & $27-46$ \\
\hline MSH6 & $10-22 \%$ & $54-63$ \\
\hline$P M S 2$ & $15-20 \%$ & $47-66$ \\
\hline
\end{tabular}


Table 3

Risk of extracolonic cancer by age 70 in Lynch Syndrome

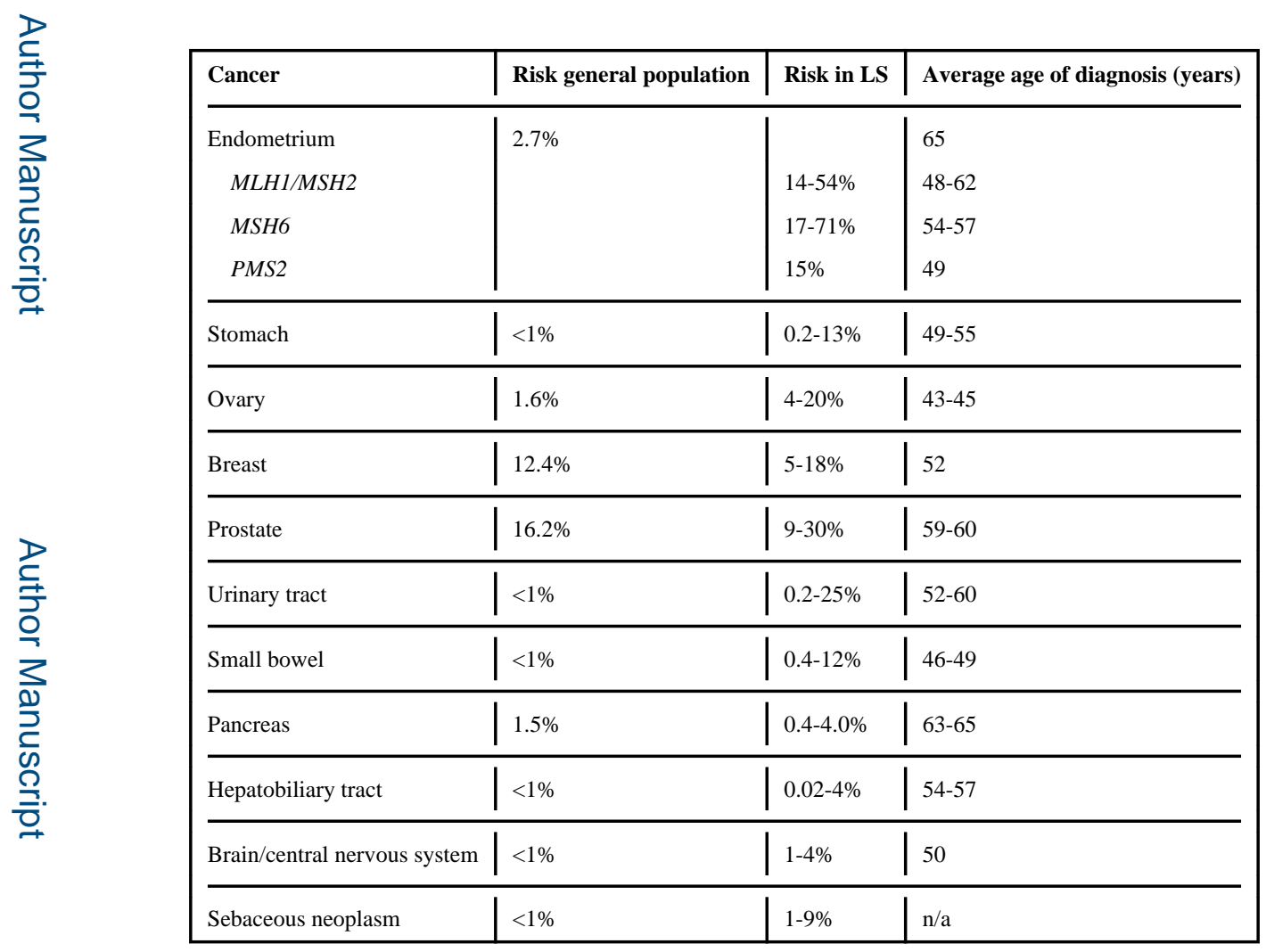


Table 4

\section{Spigelman classification for duodenal polyposis in FAP}

\begin{tabular}{|l|l|l|l|}
\hline Criteria & \multicolumn{4}{|l|}{ Points } & $\mathbf{3}$ \\
\hline & $\mathbf{1}$ & $\mathbf{2}$ & $>20$ \\
\hline Polyp number & $1-4$ & $5-20$ & $>10$ \\
\hline Polyp size $(\mathrm{mm})$ & $1-4$ & $5-10$ & Villous \\
\hline Histology & Tubular & Tubulo-villous & High-grade \\
\hline Dysplasia & Low-grade & & \\
\hline
\end{tabular}

Stage 0: 0 points. Stage I: 1-4 points. Stage II: 5-6 points. Stage III: 7-8 points. Stage IV: 9-12 points

From Spigelman AD, Williams CB, Talbot IC, et al. Upper gastrointestinal cancer in patients with familial adenomatous polyposis. Lancet 1989;2:783-5; with permission. 
Table 5

Recommendations for management of duodenal polyposis in FAP, adjusted to the Spigelman stage of duodenal polyposis

\begin{tabular}{|l|l|l|l|}
\hline Spigelman stage & Endoscopic frequency & Chemoprevention & Surgery \\
\hline Stage 0 & 4 years & No & No \\
\hline Stage I & 2-3 years & No & No \\
\hline Stage II & 2-3 years & $+/-$ & No \\
\hline Stage III & 6-12 months & $+/-$ & $+/-$ \\
\hline Stage IV & $6-12$ months & $+/-$ & Yes \\
\hline
\end{tabular}


Table 6

Indications for $A P C$ gene testing

\begin{tabular}{|l|}
\hline$\geq 100$ colorectal adenomas \\
\hline First-degree relatives of FAP patients \\
\hline$\geq 20$ cumulative colorectal adenomas (suspected AFAP) \\
\hline First-degree relatives of AFAP patients \\
\hline
\end{tabular}


Table 7

Indications for MUTYH gene testing

10 to 100 polyps (adenomas, can be mixed with serrated polyps)

Siblings of patients with biallelic MUTYH mutation

Consider: patients with early onset CRC ( $<49-55$ year) with or without polyps

Consider: children of mono- or biallelic $M U T Y H$ mutation carriers 